\title{
DC-link Voltage Regulation of Inverters to enhance Microgrid Stability during Network Contingencies
}

\author{
M. A. Hossain*, H. R. Pota, A. M. O. Haruni, and M. J. Hossain** \\ School of Engineering 83 Information Technology, The University of New South Wales, Canberra, \\ ACT 2610, Australia \\ ${ }^{* *}$ Department of Engineering, Macquarie University, Sydney, NSW-2109, Australia
}

\begin{abstract}
Equal power-rating inverters operating with different power set-points in either an islanded or grid-connected mode may lead to inter-unit circulating power caused by a large mismatch between power generation and demand during network contingencies (faults on the heavy load side or unintentional islanding). This circulating power may violate the dc-link voltage limit and, as a result, the protection scheme may shut down the inverter and reduce the microgrids reliability. This paper proposes a regulator for controlling the dc-link voltage of the microgrid's inverter during a period of circulating power. It includes a discharging resistor with a series-connected switch across the dc-link capacitor which is turned on through a control algorithm if the dc-link voltage exceeds its pre-defined limit. Case studies of parallel-connected inverters are conducted and their stability assessed through a small-signal analysis. In addition, a realistic microgrid is designed as a low-voltage (LV) network and tested to verify the concept and regulator actions presented. The simulation results validate the effectiveness of the proposed regulator during network contingencies. Keywords: DC-link voltage, islanded microgrid, droop control, supervisory controller
\end{abstract}

\section{Introduction}

Environmental and economic issues, and the insufficiency of conventional energy sources have encouraged utilities to consider alternative renewable ones. Distributed

\footnotetext{
*Corresponding author

Email address: Md.Hossain6@student.adfa.edu.au (H. R. Pota, A. M. O. Haruni, and M. J. Hossain**)
} 


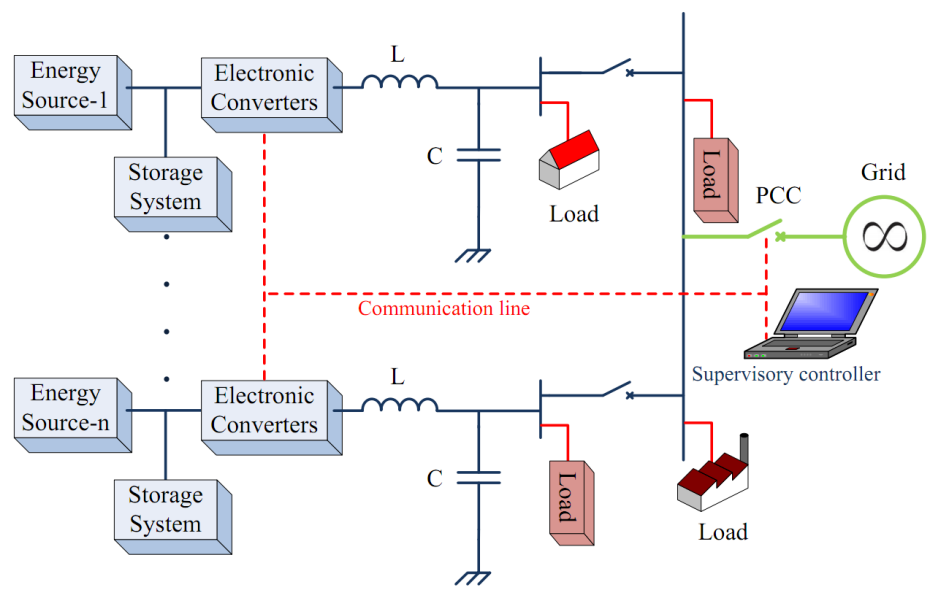

Figure 1: Microgrid architecture.

generators (DGs) in a microgrid consisting of renewable energy sources, such as wind 5 turbines, photovoltaic (PV) cells and conventional power generators, can assist to reduce power transmission and distribution losses, defer large investments in new generation and transmission lines, and increase network efficiency and reliability [1, 2]. However, as integrating DGs in distribution networks poses various technical challenges in terms of planning and operation [3, 4, 5], the concept of microgrids emerged [6]. The principal advantage of microgrids in a network is their capability to provide grid support from a remote node or operate as a stand-alone power system during grid contingencies [7, 8]. In an islanded operation, DGs are responsible for balancing the power in the network as well as regulating the magnitudes of the node voltages and system frequencies [9]. As most DG units in a microgrid are connected to the network via a voltage source inverter (VSI), controlling VSIs is an important task [10].

VSIs control the real and reactive powers as well as regulate the voltage amplitudes and frequencies of a network, often using a well-known droop control strategy [11, 12, 13]. A droop control method for DGs in stand-alone and grid-connected operations does not require internal communication among participating generators while the influence of their coefficients can be determined by conducting a smallsignal analysis [13. Droop control is able to provide a seamless transfer from a gridconnected to islanded microgrid and can operate inverters in both modes [14]. It can 
be classified as either active power/frequency (P/f) [15, 16] for inductive-dominated line impedance or active power/voltage $(\mathrm{P} / \mathrm{V})$ [17, 18] for resistive-dominated line impedance.

In a medium/high-voltage network, both conventional power generators and DGs are controlled using a reactive power/voltage $(\mathrm{Q} / \mathrm{V})$ droop strategy to provide the network with voltage support. However, in an LV one, the application of conventional control approaches is generally not appropriate since the grid voltage is coupled with changes in the active power due to the resistive nature of its transmission line [18]. Therefore, a $\mathrm{P} / \mathrm{V}$ droop control strategy is more efficient than a $\mathrm{Q} / \mathrm{V}$ one for providing voltage support [17, 18, 19, 20, 21].

In an islanded microgrid, the node voltages can deviate, based on the load power consumption of the network, from their nominal values which can be restored by changing the power set-points of the inverters. In a grid-connected microgrid, to control the inverters' output powers, their correct power set-points are chosen by the supervisory controller (Figures 1 and 2 ) which adjusts those of all the inverters before changing the state of microgrids from either grid-connected to islanded or due to the loss of heavy loads in an islanded microgrid. However, in the case of sudden loss of heavy loads in an islanded microgrid, it is not possible for a supervisory controller to promptly select power set-points as communication channels have an inherent delay [22, 23]. Note that, according to IEEE standard 1547 [24], an antiislanding controller should not delay detecting a grid failure more than $2 \mathrm{~s}$, it should However, within this time frame, a circulating current can flow from high power set-point (HPSP) inverters to low power set-point (LPSP) inverters. Then, as the dc-link voltages of LPSP inverters increase and may exceed their limits, protection scheme may shut down the inverters to prevent any damage.

Issa et al., 25], investigate a transient power effect on the dc-link voltage of an inverter for an inductive network during unintentional islanding and propose a control strategy for continuing the inverter's operation. This scheme is developed for two inverters for which a small-signal model (SSM), detailed model and practical work are validated to observe the controller's effectiveness. However, it has some 

results from case studies of two inverters and a realistic microgrid test system are discussed in Section 5 . 


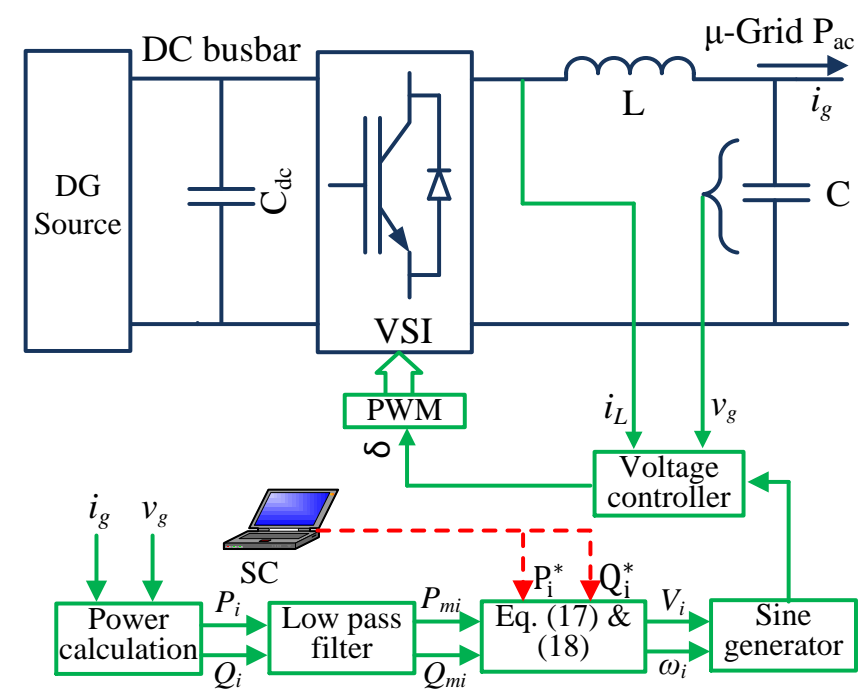

Figure 2: Control strategy for inverter.

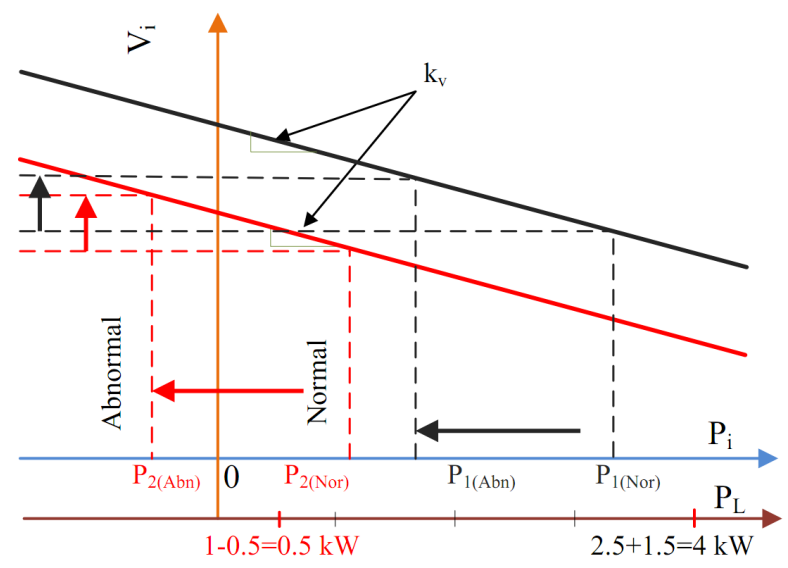

Figure 3: Droop control characteristics.

\section{Issue with droop control strategy}

During the operation of DGs in a microgrid, the power set-points of inverters with equal power rating may vary based on the optimisation process calculated by the supervisory controller. These different set-point operations of DGs may cause power to circulate among the inverters if any fault occurs on the heavy load side or there is unintentional islanding. To analyse the power importing phenomenon of an inverter in an LV line, the $\mathrm{P} / \mathrm{V}$ droop control method for a power sharing strategy 90 is employed, as shown in Figure 3.

In the operation of a grid-connected microgrid, grid-following inverters are re- 
quired to use the voltage and frequency of the grid utility as reference values. In contrast, in an islanded microgrid operation, it is essential that at least one of the grid-forming inverters generate its own voltage and frequency references. During normal operation, assuming that two inverters have equal power rating and, thus, equal droop coefficients, their power deliveries to the network is depicted in Figure 3 . If there is a network contingency (the loss of a heavy load or unintentional islanding), the power supply points of the inverters may shift to new ones where the power supply of inverter- 2 is negative, i.e. the power is imported, as shown in Figure 3. More specifically, we assume that inverters- 1 and -2 deliver power of $2.5 \mathrm{~kW}$ and $1.5 \mathrm{~kW}$, respectively, for a total load of $4 \mathrm{~kW}$. If load demand accidentally reduces to $0.5 \mathrm{~kW}$, these inverters reduce their power deliveries to $1.5 \mathrm{~kW}$ each due to equal coefficients, i.e., inverter- 2 imports $0.5 \mathrm{~kW}$ of power. The mathematical derivation for the above situation is described below.

The droop control equations for this power sharing can be written as:

$$
\begin{aligned}
& V_{i}=V_{o}^{*}-k_{v}\left(P_{m i}-P_{i}^{*}\right), \quad i=1,2 \\
& \omega_{i}=\omega_{o}^{*}+k_{\omega}\left(Q_{m i}-Q_{i}^{*}\right)
\end{aligned}
$$

where $P_{m}$ and $Q_{m}$ are the measured active and reactive powers, respectively, $P^{*}$ and $Q^{*}$ the active and reactive set/reference values, respectively, and $k_{v}$ and $k_{\omega}$ the voltage and frequency droop coefficients, respectively. The two inverters are connected in parallel and supply power to the network. As their reference output voltages are chosen to be equal, the power delivery of inverter-2 can be expressed as:

$$
P_{m 2}=P_{m 1}-P_{1}^{*}+P_{2}^{*}-\frac{V_{2}-V_{1}}{k_{v}}
$$

Adding $P_{m 2}$ to both sides of Eq. (1), the output power of inverter-2 in terms of demand can be expressed as:

$$
P_{m 2}=\frac{1}{2}\left(P_{L}-P_{1}^{*}+P_{2}^{*}-\frac{V_{2}-V_{1}}{k_{v}}\right)
$$

since the total generated power (neglecting line losses) is equal to the consumption power, i.e, $P_{L}=P_{m 1}+P_{m 2}$. Similarly, the active power of inverter-1 can be expressed 
as:

$$
P_{m 1}=\frac{1}{2}\left(P_{L}+P_{1}^{*}-P_{2}^{*}-\frac{V_{1}-V_{2}}{k_{v}}\right) .
$$

105 in the proposed control strategy, any excess voltage of the dc busbar is discharged through a resistor instead of causing an inverter shutdown, with the resistor value able to be determined from the following capacitor-discharging equation:

$$
V_{d c}=V_{o} e^{-t / \tau}
$$




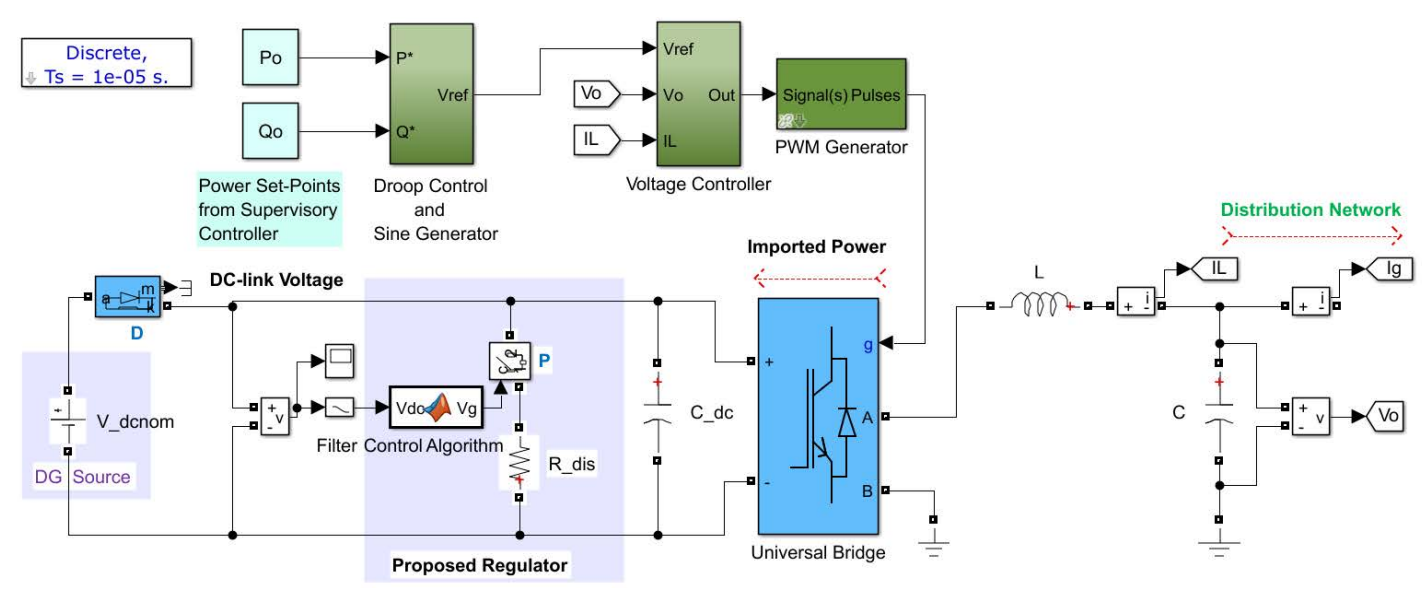

(a)

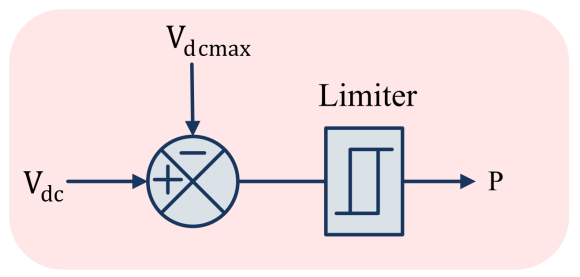

(b)

Figure 4: Proposed over-voltage regulator (a) circuit diagram and (b) control algorithm.

where the time constant, which indicates the time required to discharge the capacitor voltage to $36.8 \%$ of its initial value through a resistor, is $\tau=R_{d i s} C_{d c}$. Therefore, the maximum time delay for a signal to reach an inverter's power set-point can be incorporated to determine the resistor's value.

The control algorithm sends a signal to the switch/protection scheme to activate the discharging circuit when the normal dc-link voltage exceeds the pre-defined maximum value, say $700 \mathrm{~V}$. If the exceeded dc-link voltage decreases to its normal value due to turning on the switch, the controller deactivates the discharging circuit by sending a signal to the switch. From a high dc-link voltage to a nominal $V_{d c}$ (here, $V_{d c n o m}=400 \mathrm{~V}$ ) can be reached in one of the two ways: 1 ) discharging the capacitor's voltage or 2) adjusting the inverter's set-points. In the former, the capacitor may begin charging again if the dc-link voltage reaches the nominal value, in which case charging and discharging may happen because the controller turns on and off the switch sequentially until the imported power phenomenon is stopped. Consequently, 


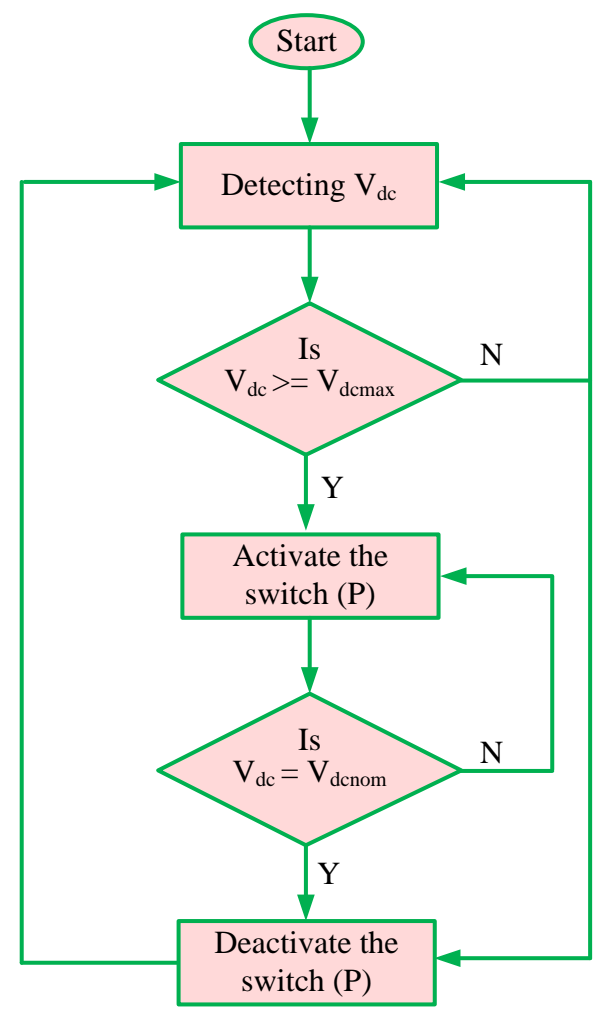

Figure 5: Operation flow chart for control scheme.

the resistor value should be selected correctly to prevent the effects of charging and discharging. For adjusting inverter set-points, the supervisory controller selects the set-points based on the optimisation process used by the energy management system.

In the proposed control strategy, the dc-link voltage can be kept within limits and, usually, increases/decreases based on the renewable sources' available power generation; for example, if the generated power increases (due to augmented sun irradiation or wind speed) to greater than the power demand, the dc-link voltage increases and vice versa [18].

\section{Small-signal model of DG units}

A microgrid is constructed considering inverters as voltage sources, the amplitudes and phases of which are controllable, in order to analyse the effect of a large load disturbance or unintentional islanding on the dc-link voltage. Figure 6 shows two inverters in an islanded microgrid sharing power with line impedance of $Z_{1} \angle \theta_{1}$ and $Z_{2} \angle \theta_{2}$. They are modelled as pure sinusoidal voltage sources because the time 


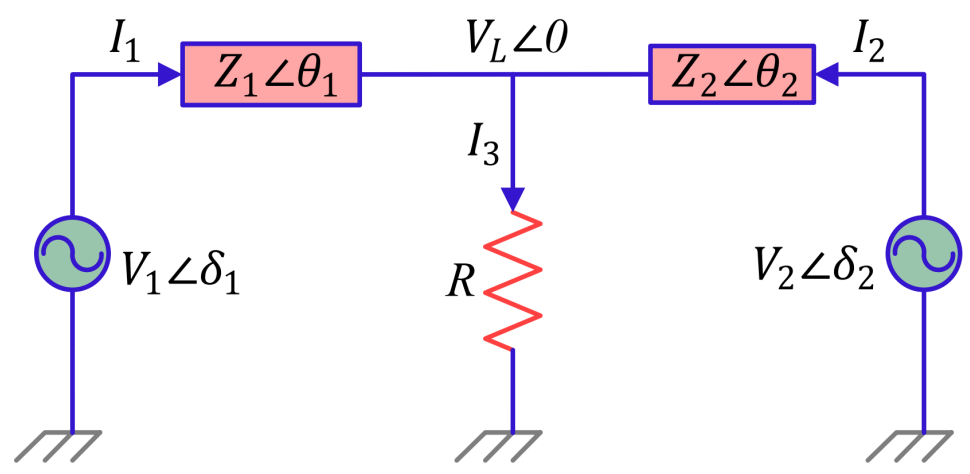

Figure 6: Two DGs connected in islanded microgrid.

response of the droop controller is much slower than that of the voltage controller, the detailed circuit diagram in Figure 2. The apparent powers supplied through lines-1 and -2 are considered $S_{1}$ and $S_{2}$, respectively, and, for simplicity, the power consumption load is treated as a resistive load (R). Applying KCL at the node in Figure 6 provides:

$$
\frac{V_{L} \angle 0-V_{1} \angle \delta_{1}}{Z_{1} \angle \theta_{1}}+\frac{V_{L} \angle 0-V_{2} \angle \delta_{2}}{Z_{2} \angle \theta_{2}}+\frac{V_{L} \angle 0}{R}=0 .
$$

This equation can be written as:

$$
V_{L}=R \frac{V_{1} Z_{2} e^{j\left(\delta_{1}+\theta_{2}\right)}+V_{2} Z_{1} e^{j\left(\delta_{2}+\theta_{1}\right)}}{R\left(Z_{1} e^{j \theta_{1}}+Z_{2} e^{j \theta_{2}}\right)+Z_{1} Z_{2} e^{j\left(\theta_{1}+\theta_{2}\right)}} .
$$

The current flowing through line-1 can be calculated as:

$$
I_{1}=\frac{V_{1} \angle \delta_{1}-V_{L}}{Z_{1} \angle \theta_{1}}
$$

Substituting Eq. (6) into Eq. (7), the current passes through the line is:

$$
I_{1}=\frac{R\left(V_{1} e^{j \delta_{1}}-V_{2} e^{j \delta_{2}}\right)+V_{1} Z_{2} e^{j\left(\theta_{2}+\delta_{1}\right)}}{R\left(Z_{1} e^{j \delta_{1}}+Z_{2} e^{j \theta_{2}}\right)+Z_{1} Z_{2} e^{j\left(\theta_{1}+\theta_{2}\right)}} .
$$

The apparent power supplied by inverter-1 can be written as:

$$
S_{1}=P_{1}+j Q_{1}=V_{1} \cdot I_{1}^{*}
$$

It is clear that Eqs. (8) and (9) are complex, which makes it difficult to solve the problem, for simplicity, the impedance is considered pure resistance. Assuming that 
$Z_{1} \angle \theta_{1}=Z_{2} \angle \theta_{2}=R_{l}$ and substituting the impedance value in Eq. (8), the inverter current can be calculated as:

$$
I_{1}=\frac{\frac{R}{R_{l}}\left(V_{1} e^{j \delta_{1}}-V_{2} e^{j \delta_{2}}\right)+V_{1} e^{j \delta_{1}}}{2 R+R_{l}} .
$$

Using Eqs. (9) and (10), the active and reactive powers for inverter-1 can be computed as:

$$
\begin{aligned}
P_{1} & =\frac{V_{1}}{2 R+R_{l}}\left[V_{1}+\frac{R}{R_{l}}\left\{V_{1}-V_{2} \cos \left(\delta_{1}-\delta_{2}\right)\right\}\right] \\
Q_{1} & =-\frac{R / R_{l}}{2 R+R_{l}} V_{1} V_{2} \sin \left(\delta_{1}-\delta_{2}\right) .
\end{aligned}
$$

In a similar manner, the active and reactive powers of inverter- 2 can be computed as:

$$
\begin{aligned}
P_{2} & =\frac{V_{2}}{2 R+R_{l}}\left[V_{2}+\frac{R}{R_{l}}\left\{V_{2}-V_{1} \cos \left(\delta_{2}-\delta_{1}\right)\right\}\right] \\
Q_{2} & =-\frac{R / R_{l}}{2 R+R_{l}} V_{1} V_{2} \sin \left(\delta_{2}-\delta_{1}\right) .
\end{aligned}
$$

To determine a relationship, if we further reduce Eqs. (11) and 12 considering $\cos \left(\delta_{1}-\delta_{2}\right)=1$ and $\sin \left(\delta_{1}-\delta_{2}\right)=\delta_{1}-\delta_{2}$, since both the $\delta_{1}$ and $\delta_{2}$ values are very small, we can write:

$$
\begin{aligned}
P_{1} & =\frac{V_{1}}{2 R+R_{l}}\left\{V_{1}+\frac{R}{R_{l}}\left(V_{1}-V_{2}\right)\right\} \\
Q_{1} & =-\frac{R / R_{l}}{2 R+R_{l}} V_{1} V_{2}\left(\delta_{1}-\delta_{2}\right) .
\end{aligned}
$$

From Eq. (15), it can be concluded that, as the active power of the inverter depends on its own terminal voltage, even if the voltage difference between terminal voltages equals zero, it will still flow. Eq. (16) reveals that the reactive power depends basically on the power angle difference and does not flow if this difference is zero. The dynamic relationship between the power angle and frequency facilitates control of the reactive power through frequency regulation. As the control approaches are used in a reverse way to the physical relationship, the power can be controlled as:

$$
\begin{aligned}
& V_{i}=V_{o}^{*}-k_{v}\left(P_{m i}-P_{i}^{*}\right), \quad i=1,2 \\
& \omega_{i}=\omega_{o}^{*}+k_{\omega}\left(Q_{m i}-Q_{i}^{*}\right)
\end{aligned}
$$


where $P_{m}$ and $Q_{m}$ are the measured active and reactive powers from the network, respectively. The $\mathrm{P} / \mathrm{V}$ droop control is superior to the $\mathrm{P} / \mathrm{f}$ one in the resistive line, as proven in [28]. The measured active and reactive powers can be obtained after passing through the sensors, where the first order dynamic transfer function of a sensor is employed to determine $P_{m i}$ and $Q_{m i}$ as:

$$
\begin{aligned}
P_{m i}(s) & =\frac{\omega_{f}}{s+\omega_{f}} P_{i}(s) \\
Q_{m i}(s) & =\frac{\omega_{f}}{s+\omega_{f}} Q_{i}(s)
\end{aligned}
$$

where $\omega_{f}=$ the cut-off angular frequency of the low pass filter in $\operatorname{rad~s}^{-1}$. The active and reactive powers supplied to the load by DG1 and DG2 can be described by Eqs. (21) to (24), respectively. A small change around the equilibrium points of the active power (Eqs. 11 \& 13) is given by:

$$
\begin{gathered}
\tilde{P}_{1}=a_{1} \tilde{V}_{1}+b_{1} \tilde{V}_{2}+c_{1} \tilde{\delta}_{1}+d_{1} \tilde{\delta}_{2} \\
\tilde{P}_{2}=a_{2} \tilde{V}_{1}+b_{2} \tilde{V}_{2}+c_{2} \tilde{\delta}_{1}+d_{2} \tilde{\delta}_{2} .
\end{gathered}
$$

Similarly, a small change around the equilibrium points of the reactive power (Eqs. $12 \& 14$ provides:

$$
\begin{aligned}
& \tilde{Q}_{1}=a_{3} \tilde{V}_{1}+b_{3} \tilde{V}_{2}+c_{3} \tilde{\delta}_{1}+d_{3} \tilde{\delta}_{2} \\
& \tilde{Q}_{2}=a_{4} \tilde{V}_{1}+b_{4} \tilde{V}_{2}+c_{4} \tilde{\delta}_{1}+d_{4} \tilde{\delta}_{2}
\end{aligned}
$$

where " " means a small change around the equilibrium points, and the coefficient ( $a, b, c$ and $d)$ values can be calculated using the following equations:

$$
\begin{aligned}
a_{1} & =\frac{1}{2 R+R_{l}}\left[2 V_{1}+\frac{R}{R_{l}}\left\{2 V_{1}-V_{2} \cos \left(\delta_{1}-\delta_{2}\right)\right\}\right] \\
b_{1} & =-\frac{R / R_{l}}{2 R+R_{l}} V_{1} \cos \left(\delta_{1}-\delta_{2}\right) \\
c_{1} & =\frac{R / R_{l}}{2 R+R_{l}} V_{1} V_{2} \sin \left(\delta_{1}-\delta_{2}\right) \\
d_{1} & =-c_{1}
\end{aligned}
$$


Table 1

System Parameters

\begin{tabular}{clcl}
\hline Parameter & Value & Parameter & Value \\
\hline$P_{1}^{*}$ & $3 \mathrm{~kW}$ & $k_{v}$ & $1 e^{-3} \mathrm{~V} / \mathrm{W}$ \\
$P_{2}^{*}$ & $1 \mathrm{~kW}$ & $k_{w}$ & $3 e^{-5} \mathrm{rad} / \mathrm{s} / \mathrm{W}$ \\
$Q_{1}^{*}$ & $0 \mathrm{var}$ & $V_{d c n o m}$ & $400 \mathrm{~V}$ \\
$Q_{2}^{*}$ & $0 \mathrm{var}$ & $V_{d c m a x}$ & $700 \mathrm{~V}$ \\
$P_{L}($ total $)$ & $4 \mathrm{~kW}$ & $k_{d c}$ & 1.25 \\
$V_{0}^{*}$ & $220 \mathrm{~V}$ & $C_{d c}$ & $2 \mathrm{mF}$ \\
$\omega_{0}^{*}$ & 314.16 & $C$ & $30 \mu \mathrm{F}$ \\
$\omega_{f}$ & $10 \mathrm{rad} / \mathrm{s}$ & $L$ & $2 \mathrm{mH}$ \\
\hline
\end{tabular}

$$
\begin{aligned}
a_{2} & =-\frac{R / R_{l}}{2 R+R_{l}} V_{2} \cos \left(\delta_{2}-\delta_{1}\right) \\
b_{2} & =\frac{1}{2 R+R_{l}}\left[2 V_{2}+\frac{R}{R_{l}}\left\{2 V_{2}-V_{1} \cos \left(\delta_{2}-\delta_{1}\right)\right\}\right] \\
c_{2} & =\frac{R / R_{l}}{2 R+R_{l}} V_{1} V_{2} \sin \left(\delta_{1}-\delta_{2}\right) \\
d_{2} & =-c_{2} \\
a_{3} & =-\frac{R / R_{l}}{2 R+R_{l}} V_{2} \sin \left(\delta_{1}-\delta_{2}\right) \\
b_{3} & =-\frac{R / R_{l}}{2 R+R_{l}} V_{1} \sin \left(\delta_{1}-\delta_{2}\right) \\
c_{3} & =-\frac{R / R_{l}}{2 R+R_{l}} V_{1} V_{2} \cos \left(\delta_{1}-\delta_{2}\right) \\
d_{3} & =-c_{3} \\
a_{4} & =-\frac{R / R_{l}}{2 R+R_{l}} V_{2} \sin \left(\delta_{2}-\delta_{1}\right) \\
b_{4} & =-\frac{R / R_{l}}{2 R+R_{l}} V_{1} \sin \left(\delta_{2}-\delta_{1}\right) \\
c_{4} & =\frac{R / R_{l}}{2 R+R_{l}} V_{1} V_{2} \cos \left(\delta_{2}-\delta_{1}\right) \\
d_{4} & =-c_{4} .
\end{aligned}
$$


Table 2

\begin{tabular}{clll}
\hline \multicolumn{4}{c}{ Operating Points } \\
\hline Variable & Value 1 & Case 2 & Case 3 \\
\hline$P_{1}$ & $2574.22 \mathrm{~W}$ & $840.80 \mathrm{~W}$ & $916.30 \mathrm{~W}$ \\
$P_{2}$ & $1400 \mathrm{~W}$ & $-333.76 \mathrm{~W}$ & $-258.23 \mathrm{~W}$ \\
$Q_{1}$ & $0 \mathrm{var}$ & $0 \mathrm{var}$ & $0 \mathrm{var}$ \\
$Q_{2}$ & $0 \mathrm{var}$ & $0 \mathrm{var}$ & $0 \mathrm{var}$ \\
$P_{L}$ & $4 \mathrm{~kW}$ & $500 \mathrm{~W}$ & $650 \mathrm{~W}$ \\
$V_{1}$ & $220.3 \mathrm{~V}$ & $221.53 \mathrm{~V}$ & $221.47 \mathrm{~V}$ \\
$V_{2}$ & $219.7 \mathrm{~V}$ & $220.94 \mathrm{~V}$ & $220.87 \mathrm{~V}$ \\
$\omega_{1}$ & $314.16 \mathrm{~Hz}$ & $314.16 \mathrm{~Hz}$ & $314.16 \mathrm{~Hz}$ \\
$\omega_{2}$ & $314.16 \mathrm{~Hz}$ & $314.16 \mathrm{~Hz}$ & $314.16 \mathrm{~Hz}$ \\
$\delta_{1}$ & $0 \mathrm{rad}$ & $0 \mathrm{rad}$ & $0 \mathrm{rad}$ \\
$\delta_{2}$ & $0 \mathrm{rad}$ & $0 \mathrm{rad}$ & $0 \mathrm{rad}$ \\
\hline
\end{tabular}

By perturbing Eqs. (17) and (18), we get:

$$
\begin{aligned}
& \tilde{V}_{i}=-k_{v} \tilde{P}_{m i} \\
& \tilde{\omega}_{i}=k_{\omega} \tilde{Q}_{m i}
\end{aligned}
$$

where $\tilde{P}_{m i}$ and $\tilde{Q}_{m i}$ are small changes around the equilibrium points in the measured active and reactive power, respectively.

By perturbing Eqs. (19) and 20), we obtain:

$$
\begin{aligned}
\tilde{P}_{m i}(s) & =\frac{\omega_{f}}{s+\omega_{f}} \tilde{P}_{i}(s) \\
\tilde{Q}_{m i}(s) & =\frac{\omega_{f}}{s+\omega_{f}} \tilde{Q}_{i}(s) .
\end{aligned}
$$

Substituting Eqs. (21) and (22) into Eq. (27) provides:

$$
s \tilde{P}_{m i}=\omega_{f}\left(a_{i} \tilde{V}_{1}+b_{i} \tilde{V}_{2}+c_{i} \tilde{\delta}_{1}+d_{i} \tilde{\delta}_{2}\right)-\omega_{f} \tilde{P}_{m i}, i=1,2 .
$$

Similarly, substituting Eqs. 23) and (24) into Eq. (28) provides:

$$
s \tilde{Q}_{m i}=\omega_{f}\left(a_{i+2} \tilde{V}_{1}+b_{i+2} \tilde{V}_{2}+c_{i+2} \tilde{\delta}_{1}+d_{i+2} \tilde{\delta}_{2}\right)-\omega_{f} \tilde{Q}_{m i} .
$$


The frequency of an inverter is related to the power angle and can be described by:

$$
s \tilde{\delta}_{i}=\tilde{\omega}_{i}
$$

Eqs. 21 to 31 can be written in terms of state-space equations in the time domain form as:

$$
\left[\dot{X}_{1}\right]=\left[A_{1}\right]\left[X_{1}\right]
$$

where state variables are given below:

$$
X_{1}=\left[\begin{array}{llllllllll}
\tilde{\delta}_{1} & \tilde{\delta}_{2} & \tilde{\omega}_{1} & \tilde{\omega}_{2} & \tilde{V}_{1} & \tilde{V}_{2} & \tilde{P}_{m 1} & \tilde{P}_{m 2} & \tilde{Q}_{m 1} & \tilde{Q}_{m 2}
\end{array}\right]^{T} .
$$

Eq. (32) represents the two inverter model in an islanded operation, with matrix ${ }_{155}\left[A_{1}\right]$ given in Appendix.

To incorporate the dc-link voltage into the state-space model of the system, the energy (E) absorbed by the capacitor can be related to the dc-link voltage as:

$$
E=\frac{1}{2} C_{d c} V_{d c}^{2}
$$

where $C_{d c}$ and $V_{d c}$ are the dc-link capacitor and voltage, respectively. Eq. (33) contains a non-linear function and, after linearising it, the dc-link voltage can be expressed in terms of power as:

$$
\tilde{V}_{d c i}=\frac{k_{d c}}{s} \tilde{P}_{i}
$$

where $k_{d c}=\frac{1}{C_{d c} V_{d c}}$.

By substituting Eqs. (21) and (22) into Eq. (34), the modified state-space model of the system can be written as:

$$
\left[\dot{X}_{2}\right]=\left[A_{2}\right]\left[X_{2}\right]
$$

where

$$
\begin{gathered}
X_{2}=\left[\begin{array}{c}
X_{1} \\
\tilde{V}_{d c 1} \\
\tilde{V}_{d c 2}
\end{array}\right] \\
A_{2}=\left[\begin{array}{ll}
A_{1} & 0 \\
A_{3} & 0
\end{array}\right]
\end{gathered}
$$

with matrix $A_{3}$ provided in Appendix. 


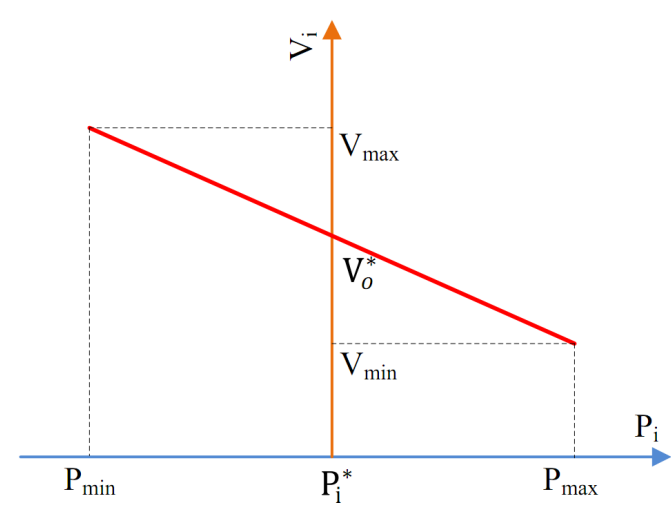

(a)

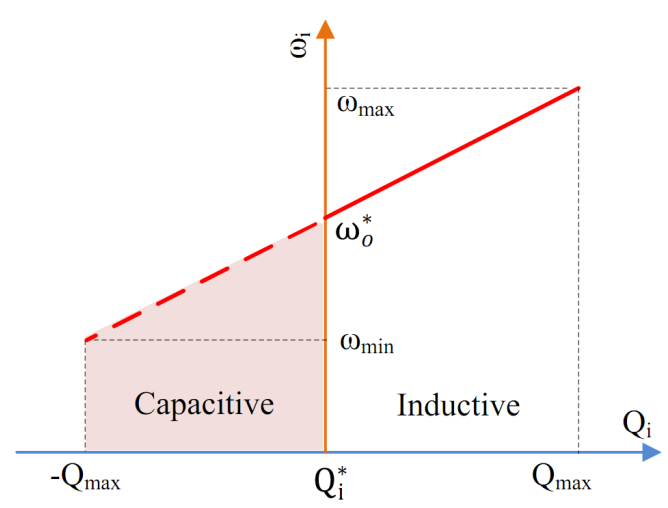

(b)

Figure 7: Droop control strategies for inverters (a) P/V and (b) Q/f.

\section{Case studies}

Simulations of the detailed model and SSM are performed using MATLAB/SimPowerSystems, and the results are compared to validate the model. In the detailed load of $4 \mathrm{~kW}$. The loads are divided into two regions, with the first assumed to contain $500 \mathrm{~W}$ for lighting purposes and the second $3500 \mathrm{~W}$ for heavy/industrial loads. The simulation parameters are listed in Table 1. In this simulation, it is assumed that the lines are pure resistance, neglecting the reactive effect on a line, and its value is $0.33 \Omega$. This assumption is true if the grid-side inductor or transformer, where output reactance is very small, is ignored. The eigenvalues of the system are $[-10,-10,-10,-10,0,0,-5,-5,0,-10,-16.7,-10]$, where all points are on the negative side of the axis, i.e., it is a stable system.

\subsection{Selection of parameter values}

As, in the test system, both the equal power-rating inverters are equipped with separate power set-points, an equal droop coefficient is chosen to validate the SSM of the DGs. The droop control coefficients can be determined from the graphical representation of the droop strategy shown in Figure 7. The mathematical relationship 
among the droop parameters can be written as:

$$
\begin{aligned}
& k_{v}=\frac{\Delta V}{P_{\text {max }}-P_{\text {min }}} \\
& k_{\omega}=\frac{\Delta \omega}{Q_{\text {max }}-Q^{*}}
\end{aligned}
$$

to calculate the equilibrium points of the developed model, which are listed in Table 2 .

The dc-link capacitor stores energy during periods of surplus power and delivers it during insufficient power generation, thereby balancing the capacitor's power flow on the dc busbar [29]. This is reflected on the dc-link voltage profile as a ripple, the voltage of which can be controlled by selecting a suitable capacitance of the dc-link capacitor that can be chosen as:

$$
C_{d c}=\frac{P^{*}}{2 \pi f V_{d c} \Delta V_{\text {rip }}}
$$

where $V_{\text {rip }}$ is the dc-link ripple voltage, the frequency of which is $2 f \mathrm{~Hz}$. As it is clear in Eq. (38) that a reduced ripple voltage increases the capacitance value and vice versa, to reduce the ripple voltage, capacitance value selected should be large.

The reference dc-link voltage is an important parameter that should be determined correctly to retain the power quality of the network as $V_{d c}$ varies around the reference value during changes in the renewable power supply [30, 31]. This value can be selected based on the two criteria: a) the power supply of the renewable sources available over a day; and b) the modulation gain of the inverters related to the terminal ac voltage as:

$$
V_{d c}^{*}=\frac{2}{\sqrt{6}} \frac{V_{a c}}{m_{g}}
$$




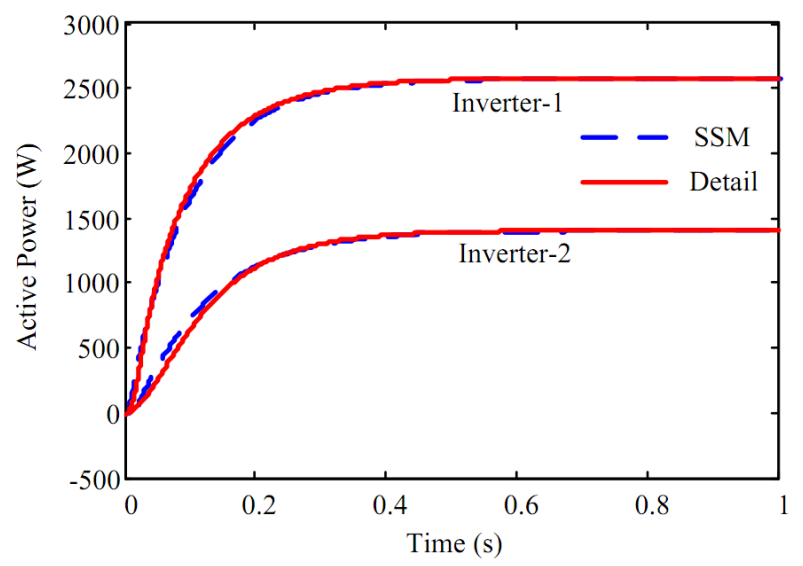

Figure 8: Active powers of inverters-1 \& -2 at $4 \mathrm{~kW}$ (case 1 ).

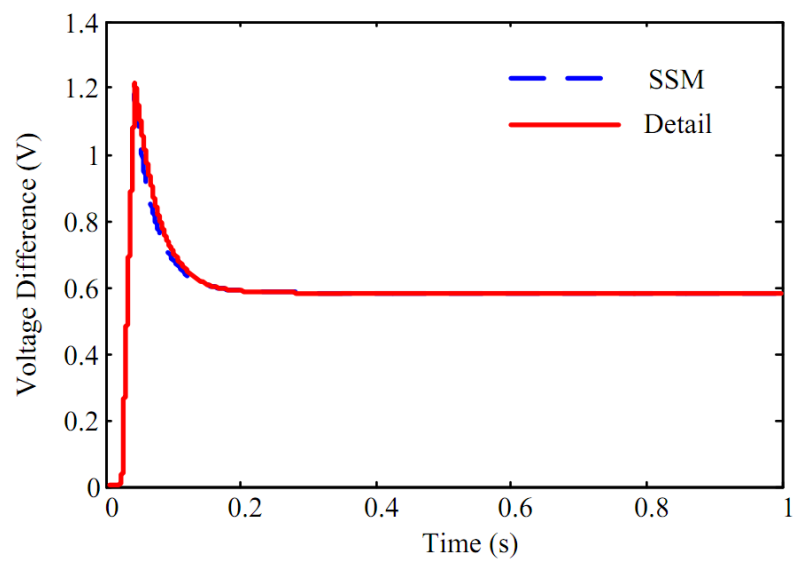

Figure 9: Voltage difference between inverters-1 \& -2 (case 1).

where $V_{a c}$ is an inverter's terminal voltage (rms) and $m_{g}$ its modulation gain which must be less than 0.57 and, conventionally, is in the range from 0.25 to 0.45 [18, 21 , 32 .

\subsection{Validation of the small-signal model}

To validate the SSM and observe the power importing phenomenon, three cases of the developed system are presented. In case 1, a normal operational mode of an islanded microgrid assuming that the power supply and demand are equal is considered. Case 2 demonstrates an abnormal situation caused by a network fault on the heavy load side where a large power demand suddenly reduces. In case 


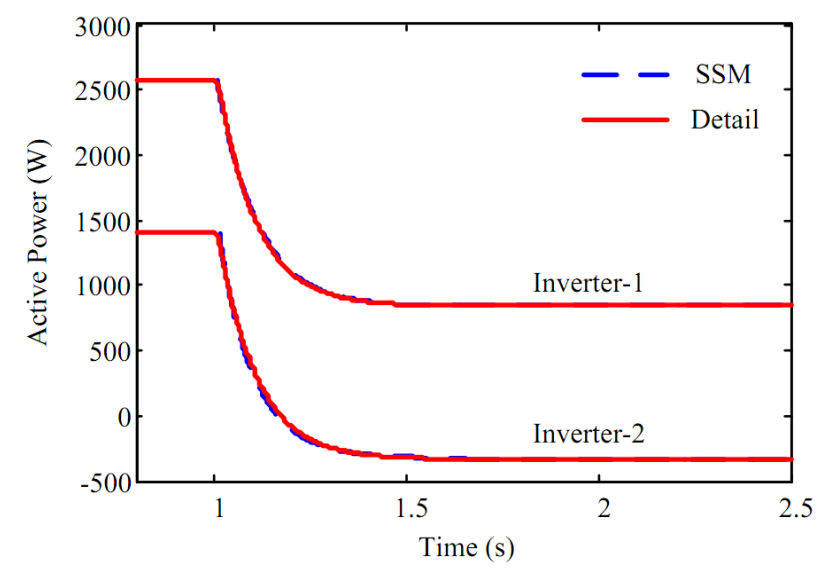

Figure 10: Active powers of inverters-1 \& -2 after disconnecting heavy loads (case 2).

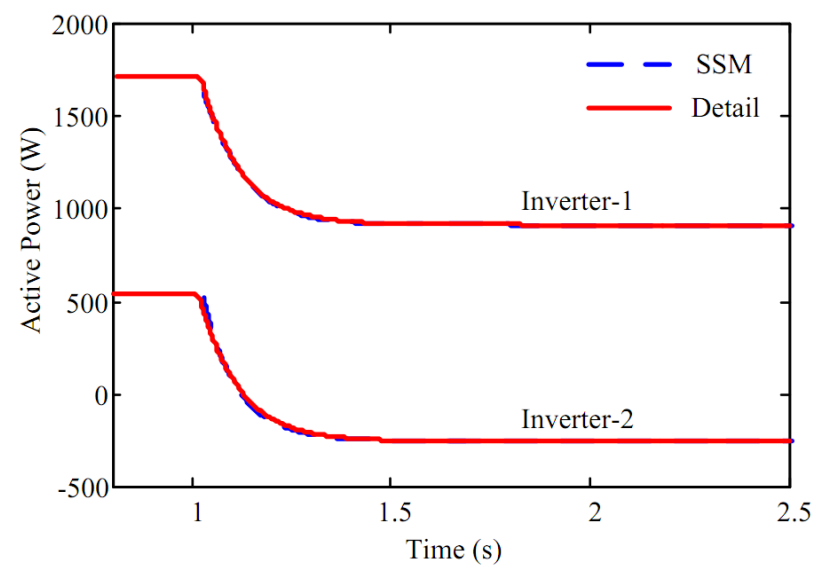

Figure 11: Active powers of inverters-1 \& -2 after unintentional islanding (case 3).

microgrid supply power to both a local load of $650 \mathrm{~W}$ and the grid, is conducted.

Case 1 (normal operation): during the supply of balanced power to the network, inverters-1 and -2 supply power of $2.46 \mathrm{~kW}$ and $1.49 \mathrm{~kW}$, respectively, for $4 \mathrm{~kW}$ of total load, as shown in Figure 8. Although the inverters' set-points are $3 \mathrm{~kW}$ and $1 \mathrm{~kW}$, respectively, they supply power after deviating from their nominal power set-points because of the application of droop control with line resistance. In a resistive network, the active power flow depends on its own voltage and difference in voltage between the two points shown in Figure 9. It is clear in Figure 8 that the results obtained from the SSM and detailed model for a balanced power supply are in complete agreement. 


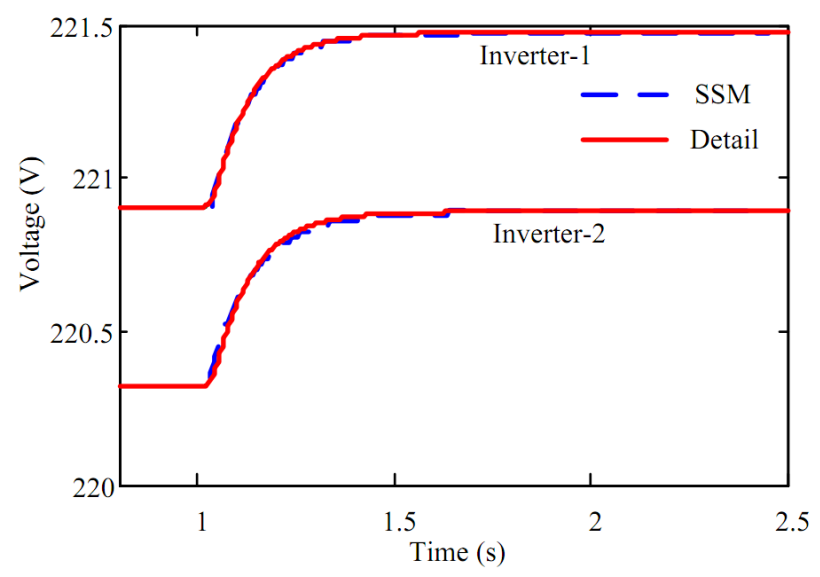

Figure 12: Terminal voltages of inverters-1 \& -2 (case 3).

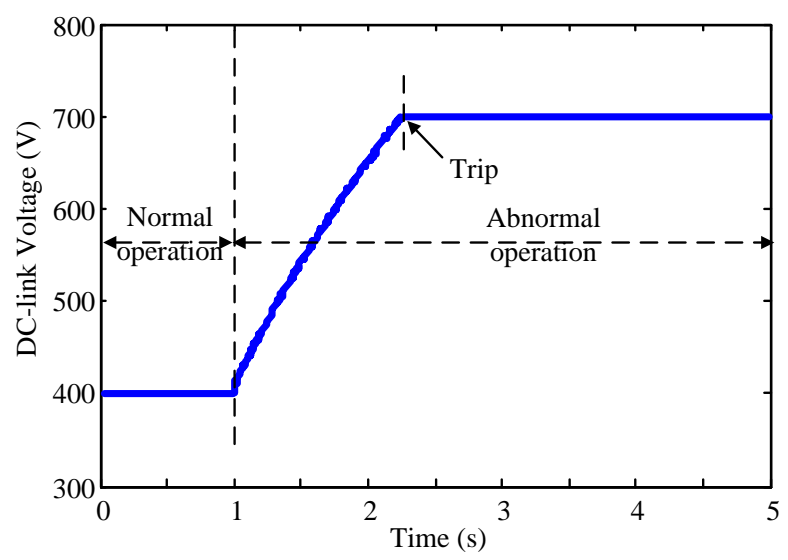

Figure 13: DC-link voltage of inverter-2 without controller (case 3).

Case 2 (operation after disconnecting heavy loads): Figure 10 demonstrates an abnormal situation in which the power demand decreases suddenly from $4 \mathrm{~kW}$ to $0.5 \mathrm{~kW}$. For the different power set-points, inverter-1 (HPSP) supplies power to both the load and inverter-2 (LPSP). During this condition, low bandwidth communication lines may delay any change in the inverter's power set-point. According to the IEEE Standard 1547 [24], this delay cannot be more than $2 \mathrm{~s}$, which can cause high voltage on the dc busbar which trips the inverter for the protection purposes.

Case 3 (unintentional islanding operation): this considers a microgrid built to support both the local consumer and the grid utility. During the grid-connected microgrid, inverters-1 and -2 supply $1.72 \mathrm{~kW}$ and $0.55 \mathrm{~kW}$ of power, respectively, to the grid and a $0.65 \mathrm{~kW}$ load. Due to unintentional islanding at $\mathrm{t}=1 \mathrm{~s}$, inverter- 
2 starts importing power from inverter-1, load consumption of which is less than the inverter-2's power set-point. The imported power, which is $258.23 \mathrm{~W}$, can raise the dc-link voltage and exceed the safe voltage limit, as shown in Figure 13 . The corresponding enhanced terminal voltage of both the inverters due to unintentional islanding are shown in Figure 12. Again, the results obtained from the SSM and detailed simulation validate the model's accuracy demonstrated in Figures 11 and 12 .

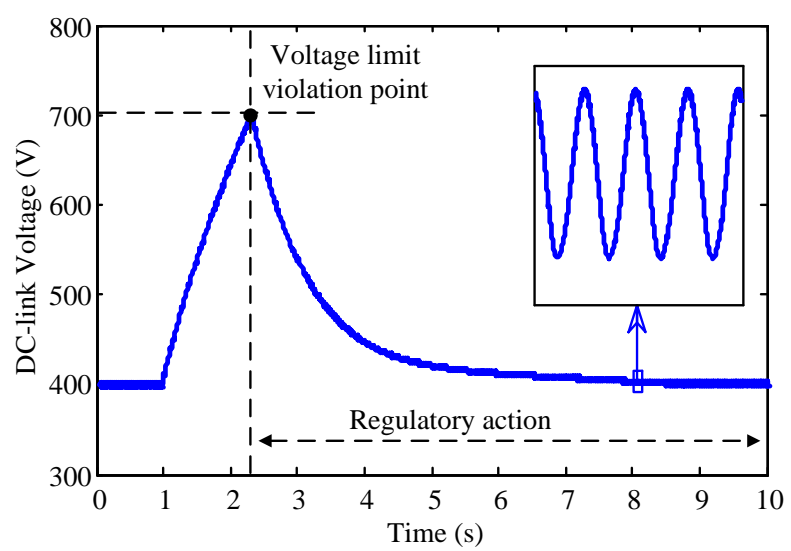

Figure 14: DC-link voltage of inverter-2 with controller.

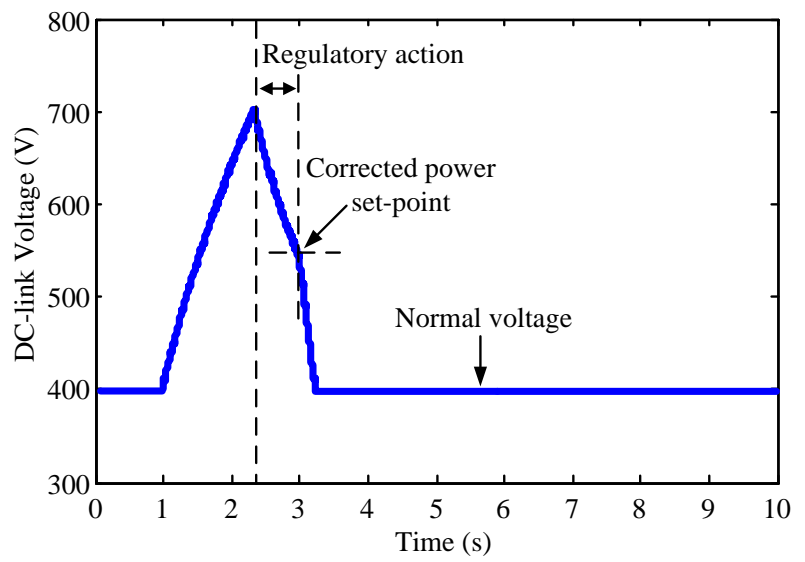

Figure 15: DC-link voltage after correcting power set-points of inverters-1 \&-2.

\subsection{Performance of the proposed over-voltage regulator}

The effectiveness of the proposed regulator is illustrated in Figure 14 . The control algorithm activates the switch if the dc-link voltage exceeds its limit and deactivates it during the nominal dc-link voltage, i.e., $400 \mathrm{~V}$ in our study. It is shown that 


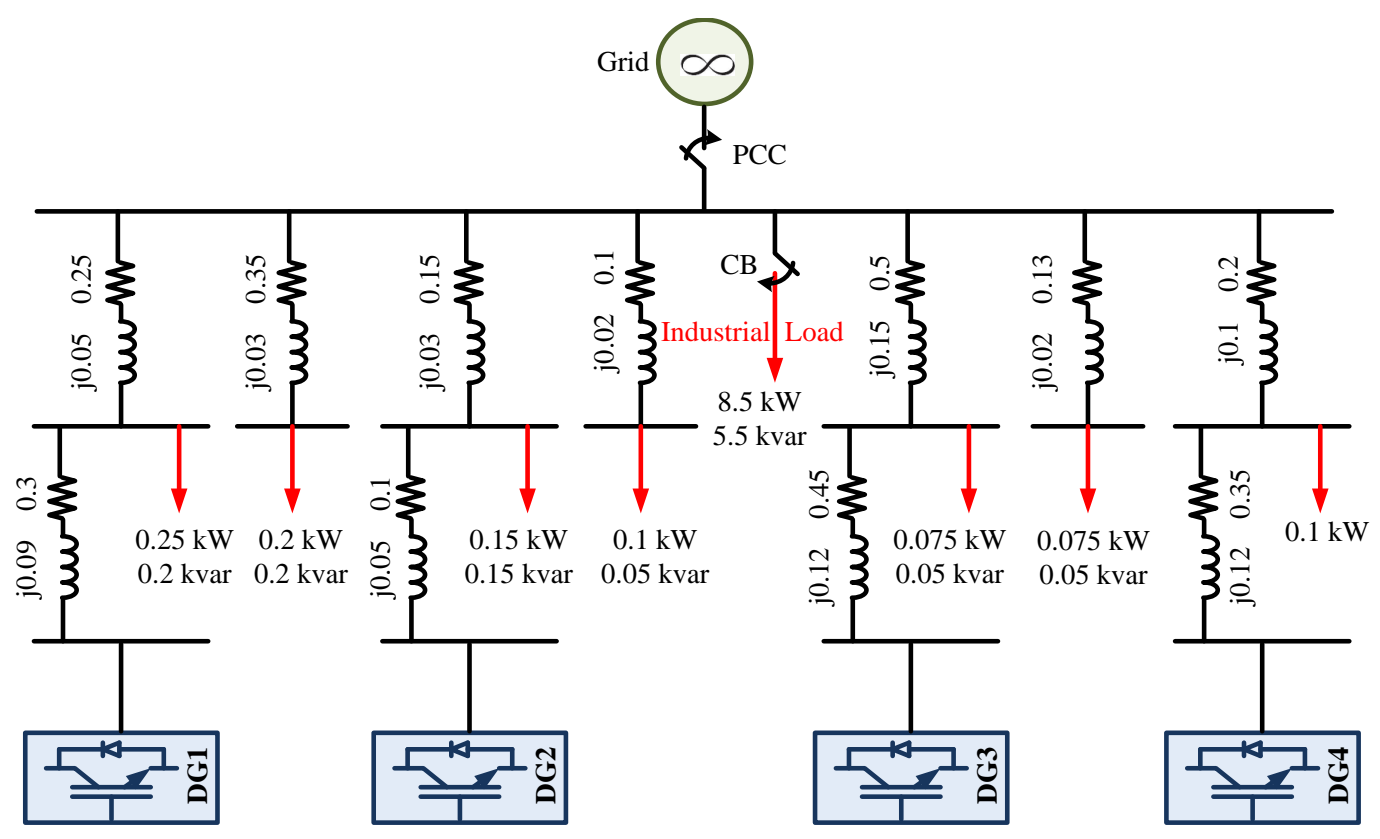

Figure 16: Realistic microgrid.

during normal operation of the inverters, the dc-link voltage is constant $400 \mathrm{~V}$, starts increasing at $\mathrm{t}=1 \mathrm{~s}$ after unintentional islanding (case 3 ) and reaches its maximum $V_{d c}$ voltage $(700 \mathrm{~V})$. The controller detects this maximum voltage and turns on the discharging circuit to discharge the excess voltage from the de busbar to protect the system against an unusual event. In this study, the discharging resistance is chosen $700 \Omega$ as this value should be comparatively high to prevent excess heat in the discharging circuit, and avoid interruption to the sensitive electronic circuits. During the discharging period, if the supervisory controller sets the inverter's power correctly, the inverter will start operating normally, as shown in Figure 15.

\subsection{Test system}

To validate the concept presented regarding the dc-link voltage in an LPSP inverter during network contingencies, a realistic microgrid is constructed, as depicted in Figure 16. The test system is developed as an LV microgrid with higher resistive than inductive characteristic in its line parameter values, as shown in Figure 16. This microgrid can be operated in both grid-connected and islanded modes. However, as both these operational conditions exhibit similar phenomena during network contingencies, only an islanded microgrid operation is considered in this 


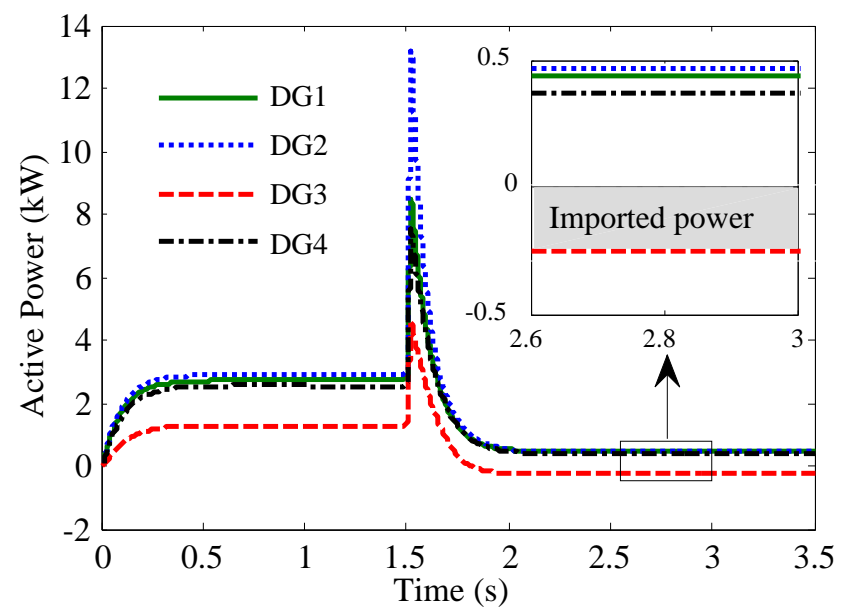

Figure 17: Active powers of four DGs during fault on lines.

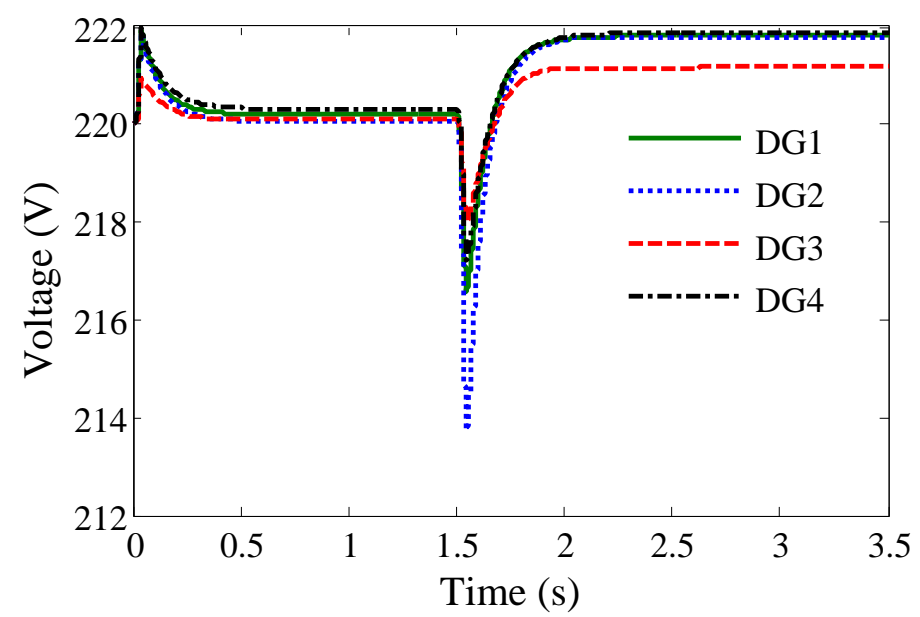

Figure 18: Terminal voltages of four DGs during fault on lines.

study. The aim is to demonstrate how, in a realistic microgrid, an LPSP inverter imports power from HPSP inverters during network contingencies and, consequently, the augmented dc-link voltage leads to a shutdown of an inverter.

Four DGs connected to the microgrid via inverters are deployed in a distribution network to provide support for both local consumers (1 kW and $0.7 \mathrm{kvar}$ ) and an industrial load (8.5 kW and $5.5 \mathrm{kvar}$ ). As all the DGs (inverters) have the same power ratings $3 \mathrm{~kW}$, they have equal droop coefficients. Three of them supply power at their maximum rating while the other needs to be operated to support the loads in the microgrid. Therefore, the power set-points chosen for DGs 1, 2, and 4 are their 


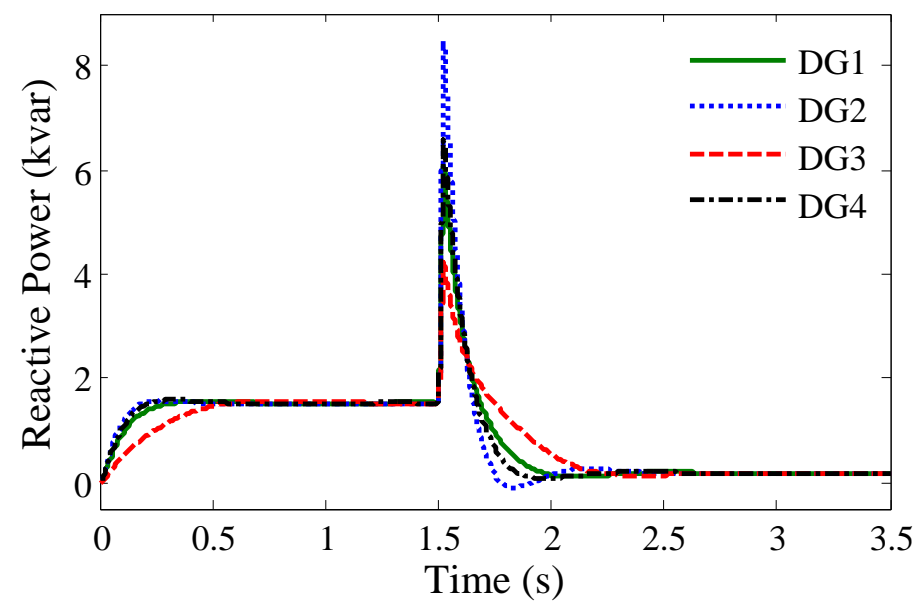

Figure 19: Reactive powers of four DGs during fault on lines.

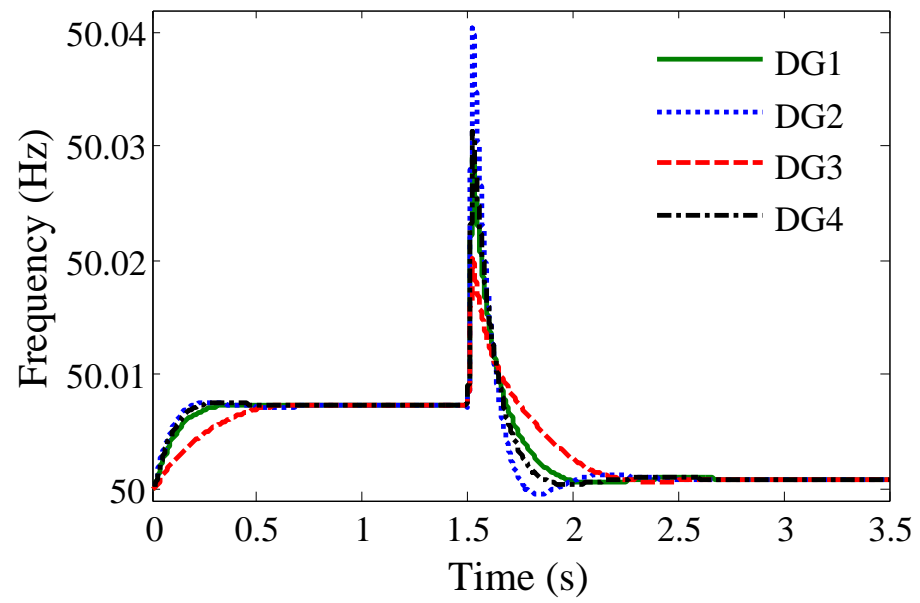

Figure 20: Frequencies of four DGs during fault on lines.

maximum rating of $3 \mathrm{~kW}$ and that for DG3 $1.3 \mathrm{~kW}$ to satisfy the power demand.

Case 1 (with proposed regulator): the aim of this case system is to justify the effectiveness of the control approaches for a low-voltage microgrid. To demonstrate the validity of this concept and its solution through the proposed control strategy, a three-phase to ground fault is introduced at $\mathrm{t}=1.5 \mathrm{~s}$ on the line of the industrial load. A relay detects the fault current and disconnects the load through a circuit breaker, with the results illustrated in Figures 17 20. Figure 17 presents active power supply of four DGs and depicts that inverter-3 (DG3) imports power from other HPSP inverters during the fault. As a result, the dc-link voltage of inverter-3 


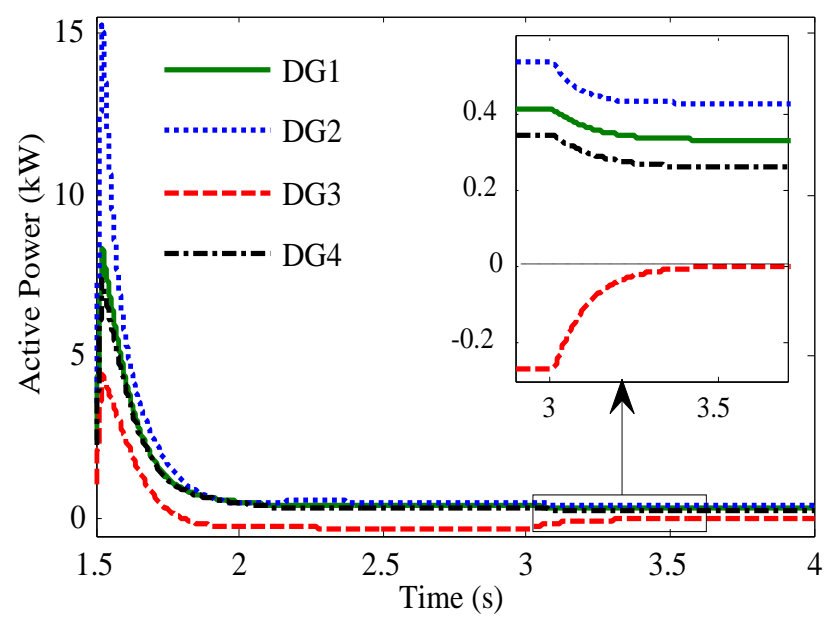

Figure 21: Active powers of DGs during shutdown of DG3.

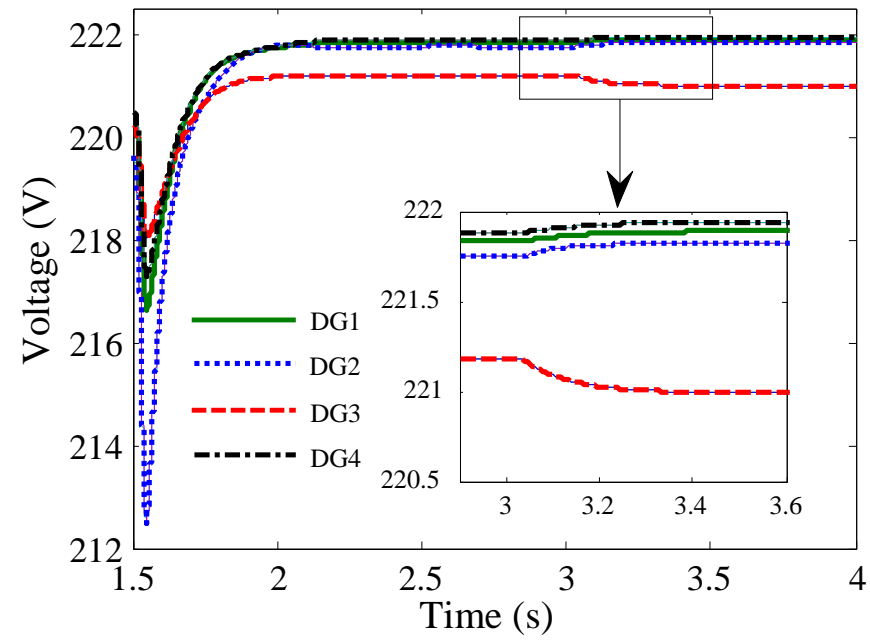

Figure 22: Terminal voltages of DGs during shutdown of DG3.

increases to maximum $V_{d c}$. In the proposed regulator, this importing power of DG3 is dissipated using a discharging resistor to maintain reliable operation of all DG units in a distribution network. During the discharging period of importing power, the supervisory controller sends signals to the power set-points of all DGs to operate them in appropriate operating conditions.

Figure 18 illustrates the terminal voltage of four DG units and from which it is shown that postfault voltage increases due to decrease in power delivery owing to the droop control phenomenon, as explained in Section 2. As frequency is a global parameter and controls the reactive power, the use of $\mathrm{Q} / \mathrm{f}$ droop control solves the 


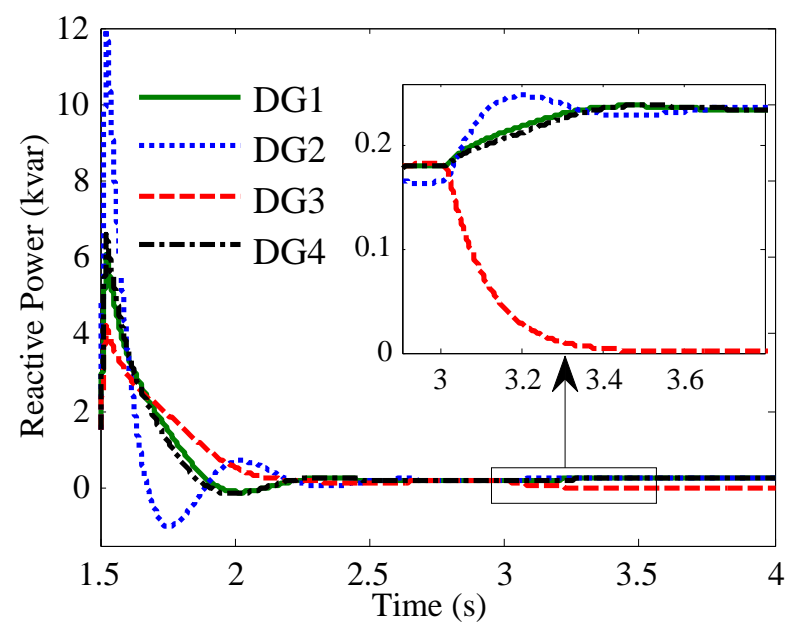

Figure 23: Reactive powers of DGs during shutdown of DG3.

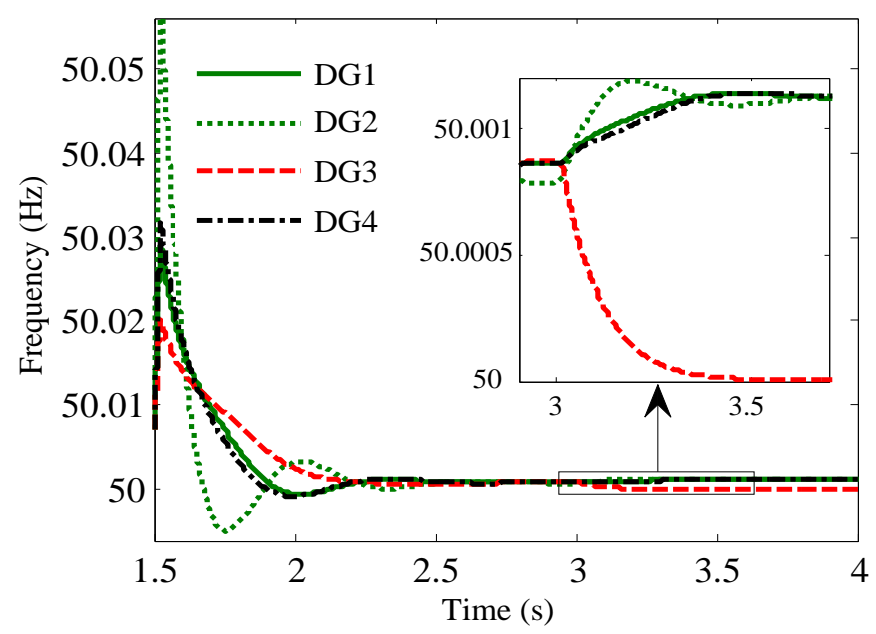

Figure 24: Frequencies of DGs during shutdown of DG3.

problems of reactive power sharing as shown in Figures 19 and 20. Each and every DG supplies similar reactive power to the network due to the equal droop coefficient. The changes of reactive loads modify the frequencies of the DGs likewise due to a positive droop control coefficient as shown in Figure 7b. It is observed that a stable microgrid operation with acceptable transient effect in an LV microgrid is achieved using a Q/f droop control strategy although the power is being imported by the DG3. From the above results it is found that the proposed controller provides excellent performance in terms of oscillation, damping and settling time.

Case 2 (without proposed regulator): the aim of this case study is to 
compare the systems response with and without the proposed regulator. If the proposed regulator is not inserted in the inverter, the imported power of DG3, as explained in Case 1, causes the dc-link voltage to increase, the protection scheme shuts the inverter down unexpectedly and as a result, active and reactive power supply of DG3 becomes zero as depicted in Figures 21 and 23. It can be observed from Figures 21 and 22 that the active powers and terminal voltages of other DG units drop and rise, respectively, due to the shutdown of DG3. Figures 23 and 24 demonstrate that the reactive powers and frequencies of other DGs increase indicating the application of the positive droop control algorithm as explained in Figure $7 \mathrm{~b}$. From the above discussion, it is concluded that without the proposed regulator, an unintentional shutdown of DG3 reduces the reliability of power supply.

This realistic microgrid validates the power importing phenomenon of an LPSP inverter during network contingencies and proves the effectiveness of the control strategy proposed for an LV network. However, this phenomenon also discloses an inherent drawback of the droop control strategies that may cause a high dc-link voltage of the LPSP inverter and, consequently, an inverter shutdown.

\section{Conclusion}

This paper investigates the dc-link voltages of equal rating inverters operating with different power set-points during network contingencies, such as the loss of large loads or unintentional islanding. During network contingencies, this voltage increases and exceeds the safe limit which causes the protection scheme to shut down the inverter. As this phenomenon decreases a system's reliability, a regulator is designed to control the dc-link voltage during a voltage limit violation and thereby protecting the inverter from shutting down. This paper also presents a small-signal analysis to determine the stability of two parallel-connected inverters in an LV microgrid. The results obtained from the SSM and detailed Simulink model are compared to validate the accuracy of the developed model. Moreover, a realistic microgrid is developed to justify the concept presented and demonstrate an inherent drawback of droop control strategies. The future aim of this research is to implement the proposed control algorithm in a small laboratory-scale microgrid 


\section{Appendix}

$$
\begin{aligned}
& A_{1}=\left[\begin{array}{cccccccccc}
0 & 0 & 1 & 0 & 0 & 0 & 0 & 0 & 0 & 0 \\
0 & 0 & 0 & 1 & 0 & 0 & 0 & 0 & 0 & 0 \\
k_{w} \omega_{f} c_{3} & k_{w} \omega_{f} d_{3} & -\omega_{f} & 0 & k_{w} \omega_{f} a_{3} & k_{w} \omega_{f} b_{3} & 0 & 0 & 0 & 0 \\
k_{w} \omega_{f} c_{4} & k_{w} \omega_{f} d_{4} & 0 & -\omega_{f} & k_{w} \omega_{f} a_{4} & k_{w} \omega_{f} b_{4} & 0 & 0 & 0 & 0 \\
-k_{v} \omega_{f} c_{1} & -k_{v} \omega_{f} d_{1} & 0 & 0 & -\omega_{f}\left(1+k_{v} a_{1}\right) & -k_{v} \omega_{f} b_{1} & 0 & 0 & 0 & 0 \\
-k_{v} \omega_{f} c_{2} & -k_{v} \omega_{f} d_{2} & 0 & 0 & -k_{v} \omega_{f} a_{2} & -\omega_{f}\left(1+k_{v} b_{2}\right) & 0 & 0 & 0 & 0 \\
\omega_{f} c_{1} & \omega_{f} d_{1} & 0 & 0 & \omega_{f} a_{1} & \omega_{f} b_{1} & -\omega_{f} & 0 & 0 & 0 \\
\omega_{f} c_{2} & \omega_{f} d_{2} & 0 & 0 & \omega_{f} a_{2} & \omega_{f} b_{2} & 0 & -\omega_{f} & 0 & 0 \\
\omega_{f} c_{3} & \omega_{f} d_{3} & 0 & 0 & \omega_{f} a_{3} & \omega_{f} b_{3} & 0 & 0 & -\omega_{f} & 0 \\
\omega_{f} c_{4} & \omega_{f} d_{4} & 0 & 0 & \omega_{f} a_{4} & \omega_{f} b_{4} & 0 & 0 & 0 & -\omega_{f}
\end{array}\right] \\
& A_{3}=\left[\begin{array}{llllllllllll}
k_{d c} c_{1} & k_{d c} d_{1} & 0 & 0 & k_{d c} a_{1} & k_{d c} b_{1} & 0 & 0 & 0 & 0 & 0 & 0 \\
k_{d c} c_{2} & k_{d c} d_{2} & 0 & 0 & k_{d c} a_{2} & k_{d c} b_{2} & 0 & 0 & 0 & 0 & 0 & 0
\end{array}\right]
\end{aligned}
$$

\section{References}

[1] W. El-Khattam, M. Salama, Distributed generation technologies, definitions and benefits, Electric Power Systems Research 71 (2) (2004) 119-128.

[2] Z. Zhang, X. Huang, J. Jiang, B. Wu, A load-sharing control scheme for a microgrid with a fixed frequency inverter, Electric Power Systems Research 80 (3) (2010) 311-317.

[3] C. Foote, G. Burt, I. Wasiak, R. Mienski, R. Pawelek, P. Gburczyk, M. Thoma, A power-quality management algorithm for low-voltage grids with distributed resources, IEEE Transactions on Power Delivery 23 (2) (2008) 1055-1062.

[4] S. A. Papathanassiou, A technical evaluation framework for the connection of DG to the distribution network, Electric Power Systems Research 77 (1) (2007) $24-34$. 
[5] M. Mehrasa, E. Pouresmaeil, B. N. Jørgensen, J. P. Catalão, A control plan for the stable operation of microgrids during grid-connected and islanded modes, Electric Power Systems Research 129 (2015) 10-22.

[6] R. H. Lasseter, Microgrids, in: IEEE Power Engineering Society Winter Meeting, Vol. 1, 2002, pp. 305-308.

[7] A. G. Tsikalakis, N. D. Hatziargyriou, Centralized control for optimizing microgrids operation, in: IEEE Power and Energy Society General Meeting, 2011, pp. $1-8$.

[8] P. M. Costa, M. A. Matos, Assessing the contribution of microgrids to the reliability of distribution networks, Electric Power Systems Research 79 (2) (2009) 382-389.

[9] M. A. Hossain, H. R. Pota, Voltage tracking of a single-phase inverter in an islanded microgrid, International Journal of Renewable Energy Research (IJRER) 5 (3) (2015) 806-814.

[10] C. K. Sao, P. W. Lehn, Control and power management of converter fed microgrids, IEEE Transactions on Power Systems 23 (3) (2008) 1088-1098.

[11] H. R. Pota, M. J. Hossain, M. Mahmud, R. Gadh, Control for microgrids with inverter connected renewable energy resources, in: IEEE PES General Meeting- Conference \& Exposition, 2014, pp. 1-5.

[12] E. Alves Coelho, P. C. Cortizo, P. F. D. Garcia, Small signal stability for single phase inverter connected to stiff ac system, in: Thirty-Fourth IAS Annual Meeting Industry Applications Conference, Vol. 4, IEEE, 1999, pp. 2180-2187.

[13] E. A. A. Coelho, P. C. Cortizo, P. F. D. Garcia, Small-signal stability for parallel-connected inverters in stand-alone ac supply systems, IEEE Transactions on Industry Applications 38 (2) (2002) 533-542.

[14] M. A. Abusara, J. M. Guerrero, S. M. Sharkh, Line-interactive ups for microgrids, IEEE Transactions on Industrial Electronics 61 (3) (2014) 1292-1300. 
[15] M. C. Chandorkar, D. M. Divan, R. Adapa, Control of parallel connected inverters in standalone ac supply systems, IEEE Transactions on Industry Applications 29 (1) (1993) 136-143.

[16] J. Peas Lopes, C. Moreira, A. Madureira, Defining control strategies for microgrids islanded operation, IEEE Transactions on Power Systems 21 (2) (2006) 916-924.

[17] H. Laaksonen, P. Saari, R. Komulainen, Voltage and frequency control of inverter based weak LV network microgrid, in: International Conference on Future Power Systems, IEEE, 2005, pp. 6-pp.

[18] M. A. Hossain, M. I. Azim, M. A. Mahmud, H. R. Pota, Active power control in an islanded microgrid using dc link voltage status, in: IEEE Innovative Smart Grid Technologies-Asia (ISGT ASIA), 2015, pp. 1-6.

[19] A. Engler, N. Soultanis, Droop control in LV-grids, in: International Conference on Future Power Systems, IEEE, 2005, pp. 6-pp.

[20] Y. W. Li, C.-N. Kao, An accurate power control strategy for power-electronicsinterfaced distributed generation units operating in a low-voltage multibus microgrid, IEEE Transactions on Power Electronics 24 (12) (2009) 2977-2988.

[21] T. L. Vandoorn, J. D. De Kooning, B. Meersman, B. Zwaenepoel, Control of storage elements in an islanded microgrid with voltage-based control of DG units and loads, International Journal of Electrical Power \& Energy Systems $64(2015)$ 996-1006.

[22] J. He, C. Lu, X. Jin, P. Li, Analysis of time delay effects on wide area damping control, in: Circuits and Systems, 2008. APCCAS 2008. IEEE Asia Pacific Conference on, IEEE, 2008, pp. 758-761.

[23] F. Liu, H. Gao, J. Qiu, S. Yin, J. Fan, T. Chai, Networked multirate output feedback control for setpoints compensation and its application to rougher flotation process, IEEE Transactions on Industrial Electronics 61 (1) (2014) 460-468. 
[24] IEEE standard for interconnecting distributed resources with electric power systems, IEEE Std 1547-2003 (2003) 1-28doi:10.1109/IEEESTD. 2003.94285.

[25] W. R. Issa, M. Abusara, S. M. Sharkh, Control of transient power during unintentional islanding of microgrids, IEEE Transactions on Power Electronics 30 (8) (2015) 4573-4584.

[26] R. Dugan, R. Zavadil, D. Van Holde, Interconnection guidelines for distributed generation (2002).

[27] E. Koutroulis, J. Chatzakis, K. Kalaitzakis, S. Manias, N. C. Voulgaris, A system for inverter protection and real-time monitoring, Microelectronics journal 34 (9) (2003) 823-832.

[28] J. Au-Yeung, G. M. Vanalme, J. M. Myrzik, P. Karaliolios, M. Bongaerts, J. Bozelie, W. L. Kling, Development of a voltage and frequency control strategy for an autonomous LV network with distributed generators, in: Proceedings of the 44th International Universities Power Engineering Conference (UPEC), IEEE, 2009, pp. 1-5.

[29] Y. Hu, Y. Du, W. Xiao, S. Finney, W. Cao, Dc-link voltage control strategy for reducing capacitance and total harmonic distortion in single-phase gridconnected photovoltaic inverters, Power Electronics, IET 8 (8) (2015) 13861393.

[30] P. Goli, W. Shireen, Control and management of PV integrated charging facilities for PEVs, in: Plug In Electric Vehicles in Smart Grids, Springer, 2015, pp. $23-53$.

[31] C.-Y. Tang, Y.-F. Chen, Y.-M. Chen, Y.-R. Chang, Dc-link voltage control strategy for three-phase back-to-back active power conditioners, IEEE Transactions on Industrial Electronics 62 (10) (2015) 6306-6316.

[32] M. A. Abusara, S. M. Sharkh, J. M. Guerrero, Improved droop control strategy for grid-connected inverters, Sustainable Energy, Grids and Networks 1 (2015) 10-19. 